\title{
DECONSTRUCTING TOTALITARISM: FRAGMENTING THE WHOLE IN NARRATIVES
}

\author{
Hilda Gairaud Ruiz.
}

\begin{abstract}
RESUMEN
El siguiente artículo examina la fragmentación dentro del contexto de sistemas totalitarios en general y en narrativas y su representación. Dicho análisis contempla dos acercamientos opuestos del término, su aparente deconstrucción y las implicaciones que conlleva esta redefinición dentro de una interpretación literaria y fuera de ella.

Palabras clave: sistemas totalitarios, fragmentación, deconstrucción, narrativas.
\end{abstract}

\begin{abstract}
The following article examines fragmentation within totalitarian systems, in general, and in narratives, and its representation. The analyzes focuses in two opposing approaches to the term and its apparent deconstruction, as well as the implications that a new view of this term could mean in terms of literary interpretation and elsewhere.

Key words: totalitarian systems, fragmentation, deconstruction, narratives.
\end{abstract}

Recepción: 16-7-04

Aceptación: 6-12-04 


\section{Conceptualization of Fragmentation}

\subsection{Introducing Wholeness}

Lately, postmodern writing has been associated with fragmentation, either by linking the term to style or to the description that writers offer of reality. Though the notion of fragmentation remains vague for many critics and writers, many authors have adopted some of its proposals to enhance thematic development. Therefore, an exploration of the notion of fragmentation has become a challenge. The innovating use of fragmentation in descriptions or in narratives has certainly served to bring into consciousness the realities of a generation of American writers who have opted to employ it as a narrative strategy that mirrors a compartmentalized view of reality where ideological differences are hardly (if not) acknowledged. By framing discourse using fragmentation, writers articulate experience generating and processing texts distancing from traditional literary and ideological conventions. The new forms of style propose different means of presenting, shaping, and controlling the representations of experience. Within this frame, the descriptions of characters and their realities often appear as spare, disconnected, and unanchored. Thus, the employment of new, innovating, and different techniques and devices in narratives support the thematic issues of decentering, deconstructing, and fragmenting traditional ideological conventions specially in literature and in some cultural practices attached to fixed, stable social institutions such as marriage, parenthood, family, and labor among others. By utilizing a fragmented style in discourse, writers reveal an interpellation to their audience to acknowledge difference, and the proposals of the new politics of difference, which aim the recognition of those cultural practices that have been distanced from an hegemonic center and have been marginalized in ideology but that are also an important part of it and, thus, must be seen as part of the system.

In order to study the employment of fragmentation as a stylistic narrative device, the revision of theoretical proposals surrounding the term (since there is no theory of fragmentation so far) becomes a must. In the past, the term "fragmentation" had been linked to a disrupting principle that opposes an idea of wholeness or the conformation of an unified and totalitarian system. Nevertheless, recently the notion of fragmentation has been revised. New proposals have distanced fragmentation from separation and isolation. In general terms, now fragmentation becomes a means to represent the heterogeneous, plural composites of contemporary social and cultural environments, which oppose traditional prevailing monolithic systems of thought. Traditionally, fragmentation had appeared as the disruption of unique and empowering ideologies. "Unique empowering ideologies" refer to what contemporary critics have envision as the "issues of political power, sexuality, and class [assuming] that a text [and discourse in general] embodies, to some degree, the ideologies prevailing in its society" (Makaryk 1994: 558). In this sense, according to these critics, texts represent descriptively "an explicit or tacit sharing of certain attitudes, values, assumptions, and ideas" (Makaryk 1994: 558). Ideology present in texts, then, becomes the revelation of "all the perceptions, attitudes, and behaviors which both result from and contribute to an individual's conceptualization of his/her position in a social context" (Meyers, Pacheco 2003: 44). Therefore, if ideology is "inscribed in specific discourses [and] a discourse is a domain of language-use, a 
particular way of talking (and writing and thinking)" (Belsey 5), it certainly serves as the means to legitimate and validate dominant social structures, as Marxist literary criticism has affirmed: "ideology is one of the means, perhaps the dominant one, by which a society maintains its economic and political status quo" (Childers 558). Unique empowering ideologies become those that control all of the social means of production, either artistic, economic, or literary and that manipulate the personal interactions present in discourse through which social behaviors and worldviews are framed.

Within this frame, dominant prevailing ideology comes to represent a harmonic whole. In itself, it embodies wholeness or totality and fragmentation becomes a force that resists that totalitarian " imposing, uniform and harmonious whole" (Childers 1995: 510). The whole frames ideology into one prevailing and legitimate system in which the political, economic, cultural, religious, and philosophical currents follow one closed structure of power. Nonetheless, in order to understand fragmentation, a revision of wholeness becomes necessary.

Historically, ideas of wholeness and totality have been approached in different ways. In the first place, the notion of totality is linked to essentialism in a metaphysical realm. Objects in this realm are constituted by a certain essence or properties that determine an idea of wholeness. Examples of these objects involve the idea of God, religion, and political ideologies, each of which possesses specific characteristics: "no matter what their definition or description, objects have properties that are timeless and immutable, and these properties not only are requisite to their existence but are expressed in their definitions or descriptions" (Childers 1995: 100). The properties are fixed, unchangeable and mostly determined by the mainstream thought. They are often linked to an absolute idea of truth about human nature, and this truth determines human behavior. As a consequence, any other approach to the object or any attempt to explore the object/subject differently from the mainstream thought is seen as a threat to this idea of truth. Attempts to ignore, modify or question the properties of the object/subject are considered anti-humanist attempts at disruption. Hence, disruption of the official beliefs surrounding objects/subjects becomes transgression, since it tends to "deny the existence of an essential human nature, a metaphysical starting point [such as God] or the emancipatory claims of determined political systems" (Childers 100). The properties of objects/subjects which determine the whole, include moral, ethical, and religious standardized values that serve as the manifestations of underlying structures, and define mainstream thought and behavior in any cultural system at any given time. This idea of wholeness shaped by essentialism perceives disruption as fragmentation in a very negative way because any opposition to an essential truth attempts to break the harmonious order of elements. In this sense, the idea of wholeness may be represented by the traditional ways through which writers frame discourse and describe traditional religious values and properties such as marriage, family life, parenthood and subjects in general, which are threatened by inevitable changes in ideological frames within the passing of time.

\subsection{Totality, The Whole in Hegemony}

Another perception of totality is the materialistic philosophical approach upon which Marxism bases its foundations. According to Marxist materialistic philosophy, the term totality refers to the assumptions that cultural and intellectual productions are articulations 
of the dominant class in any social environment. A definition of hegemony states that "the cultural and intellectual productions are ideological, attempting to produce a narrative of a unified social totality that, by Marxist accounts, is essentially contradictory and unstable" (Childers 1995: 175). In a broader sense, hegemony is also regarded as "dominance, leadership exercised over others" (Meyers 2003: 44). Hegemony portrayed in literature follows the discourse of the literary cannon mentioned by Paul Lauter in Critical Theory and Practice: A Coursebook written by Keith Green and Jill Lebihan as a "product [...] of our training in male (patriarchal), white, bourgeois cultural tradition, including in particular the formal techniques of literary analysis" (274). Hegemony portrays the characteristics of totalitarian systems: "the dominance of one group, nation, or culture over another" (Childers 1995: 131). In the twentieth century, totality "has acquired the connotation of political dominance, especially in regard to the activities of superpowers" (Childers 1995: 131). Likewise, Antonio Gramsci proposes hegemony as a representation of "the set of values and beliefs through which the ruling class exercises its power over the masses, including religion, education and media" (Makaryk 1994: 344) Correspondingly, Barthes states that hegemonic ideas are "the common sense or myths that govern a society and to which the masses freely consent; this consent would likewise have to be accorded to any ruling group" (Makaryk 1994: 344). Both Gramsci and Barthers consider hegemony as form of authenticate relations of political and economic power in ideology. Subsequently, the social institutions and cultural agents who control these relations are in charge of preserving them through the establishment of totalitarian systems. Totality within this context is then linked to essentialism, for it presents a dominant political system as legitimate and monolithic. An effective means to accomplish legitimatization and preservation is discourse. In this direction, Barthes affirms that value systems become encoded in language and in social usages. He stated that:"experiences (arrangements) reflect a pattern based on stereotypes, which is passed on through a particular culture". Because dominant intellectual producers control ideological output, literature and history become a "seamless unity or whole" (Makaryk 1994: 245). Hence, hegemony in literary discourses has serve its aim: to control forms of artistic and aesthetic productions in order to preserve a prevailing ideology.

However, contradictory qualities of totality pointed out formerly also embody resisting forces, ideology-wise, which are negated by hegemonic groups. Contradictions underline the conflict between social classes or cultural groups, their ideologies and hegemonic forces. The conflict provokes the questioning of the representation of the whole. This questioning provides the opening up to a wide range of possibilities of ideological discourses which consequently fragment hegemony. Fragmentation, then, appears first as the struggle for representation and recognition in any social group in conflict with other forces. In this context, fragmentation might take the form of resistance and subversion. In narratives, hegemony is implicitly represented in the prevailing, dominant ideology, and fragmentation is represented by the clash of different, alternate, cultural behaviors which, depending on specific interests, search for types of personal power.

Culturally, hegemony has been challenged in many different ways throughout history. Specifically, in marriage, parenthood and family issues, in general, for example, a hegemonic representation of a typical American family has historically been linked to the bourgeois, religious, mainly Puritan, ideology. In his book, Sociology, sociologist Arthur Green defines the American family: "Husband, wife, and children if any make up a typical household. Ours is a restricted conjugal family form, and for that reason its emotional ties are 
uniquely close" (1952: 370). Furthermore, Green also sustains that the traditional American family structure has been supported by the four main religious faiths in the United States: the Catholics, the Protestants, the Jews and a fourth major group called the secular humanist. Green affirms, "It is no accident, that where orthodoxy is found in modern America there also will be found a semblance of the traditional family [...] Periods of stable religionism are also periods of stable familism" (1952: 377). So, the dysfunctionality of this hegemonic idea of a functional family in the United States nowadays suggests its fragmentation. Besides, the representation of hegemony is established by the struggle for social recognition, control, and economic power among characters, competing among themselves disrupting, at times, absolutist prevailing ideas embodied of truth. In addition, from a materialistic point of view, the social pressures to achieve financial solvency and status have become part of the experience of Americans in the U. S. society and have certainly affected the functioning of the family. According to Green, nowadays, each family member is forced to achieve financial independence and social recognition. As a consequence, family members leave the family nucleus in search of personal interests, provoking its fragmentation. Thus, the hegemonic family frames fragments. Following, like hegemony, the notion of the center will be theoretically analyzed.

\subsection{Totality and Centered Structures: The Struggle between the Center and the Margin}

Like essentialism and hegemony, the notion of the center constitutes a version of wholeness. Joseph Childers and Gary Hentzy mention structuralists like the French philosopher Jacques Derrida who explains totality and wholeness directly linked to the notion of the center. In his essay "Structure, Sign, Play in the Discourse of the Human Sciences," Derrida states that "the figure of the centered structure is as old as Western thought itself, and the concept of center has inevitably functioned as an origin, end, or fixed point, which serves to balance and organize the structure as a whole, as well as to limit the play of that structure" (1995: 72). He also adds that "the notion of a structure lacking any center represents the unthinkable itself" (72). As in essentialism, the center always takes the form of "an essence, a god, or a concept of reason" (72), and this form makes reference to the "philosophical attempts to establish indisputable first principles as a foundation for all knowledge" (186). The center becomes a totalitarian, hegemonic structure which controls the mainstream of social behavior.

But just like the Marxist argument of the contradictory state of totalitarian systems, other forces operating within centered systems tend to unbalance powerful foundations, thus generating contradictions and differences: "for in order to provide in any system a stable point of reference that governs the constitution of the structure, the center must be at once a part of that structure and an Archimedean point standing outside of it" (Childers, Hentzi 1995: 72). According to Derrida, the tendency of modern thought is to move away from the "disabling or coercive qualities inherent in systems of thought through an effort of decentering that exposes the contradiction inherent in such concepts" (72). The practices of decentering have become frequent in contemporary literary criticism, for the notion of totality and whole will always be challenged by other forces established by difference from the centered figure. Within this context, the whole appears positively fragmented, for fragmentation accounts for difference, and difference makes reference to all other possible foundations of cultural and ideological 
thought operating in systems. In short, the center becomes the point that expands towards the margins where differentiation and recognition take place.

An example of center is implicitly represented by traditional values surrounding families anywhere -the typical patriarchal, married, and monogamous couple and its biological children. The traditional values framing family life often clash with other current realities, like the ones represented in the descriptions of reality in narratives nowadays: single motherhood, divorced parents, children taken care by outsiders, to exemplify. As part of ideology too, these other family frames provoke the fragmentation of the center. Fragmentation is then represented by the acknowledgment of different ideologies and the subsequent disruption caused to traditions and hegemony. Currently, fragmentation appears in a negative way, for it is generally presented as opposing the whole and not acknowledging difference.

\section{Deconstructing the Center, Fragmenting the Whole}

\subsection{Deconstruction}

The idea of totality is also affected by contemporary ideas of deconstruction. Jacques Derrida explains the notion of deconstruction and the metaphysical systems that have controlled the center throughout history. He states that:

\footnotetext{
metaphysical systems are centered structures that depend on a paradoxical logic according to which the center is understood as both present in, and independent of, the structure. In its simplest form, the relationship between the center and the structure appears as a hierarchical opposition in which one term is understood to embody truth and the other is seen as merely a pale copy (Childers 1995: 74).
}

The center structure accounts for one privileged present term and its absent opposite. The privileged term and its position in relation to its opposite in the structure develop what Derrida has called logocentrism: one term of the binary opposition embodies a privileged condition while its opposite appears merely as a supplement. The two terms fall into a "hierarchical relationship" of presence/absence, superiority/inferiority. Derrida explains the operation of the logic of the supplement: all metaphysical systems, no matter what term they offer as embodying presence, have a need of a supplementary term which compensates for the absence of this source (absence/presence) [...], however, in each case the supplement actually can be seen to undermine this hierarchical relationship (Childers 1995: 296). The purpose of deconstruction is to subvert this hierarchical relationship: "instead of appearing as a mere representation of truth [...] the privileged term is obscured by the supplement, providing a field of limitless play, which is characterized by the movement of difference" (Childers 1995: 74). In other words, the possibilities of different objects and agents to place themselves in the system expand to the point of becoming re-positioned in more privileged places. Thus, logocentric thought is demystified providing a wide range of possibilities of inquiry and questioning, establishing new "meaningful historical or cultural distinctions between one metaphysical system and another" (Childers 1995: 75). Through this process, the features of the whole in metaphysical systems fragment into other systems of equal importance and validity. Fragmentation, therefore, is positive within 
the notion of deconstruction, for it disrupts logocentric thought, providing spaces for new ways of experiencing and perceiving. In this perception, terms and propositions are revised, provoking a questioning of hierarchies.

Logocentrism may account for the absolutist ideas surrounding the traditional family lifestyle, which is shattered by many outside agents, considered of seemingly minor importance. "Outside agents" (Green 1952: 324) refer to the ideological and cultural objects which have caused changes and fragmentation in families, such as mobility, labor, economic factors and others. However, each member of a family, for example, may have a cultural history, which is not often the history of others. Hence, inside agents, family members and their circumstances, may also clash among themselves, causing fragmentation and separation within its members. However, the fragmentation of the family needs to be implemented by the notion of borderlands. This latter proposal leads to a new exploration of the values and new ways of relating, based on principles of mutual understanding.

\subsection{Exploring Fragments}

Totalitarian systems, whether essentialist, hegemonic, or centered, have been bombarded by current ideological and socio-cultural forces, causing the fragmentation of totality. These forces usually represent social sectors that have not been acknowledged by totalitarian ideology, and, consequently, have resisted discrimination, and struggled for recognition. The results of the struggle have provoked a fragmentation of the system. Every fragment of any ideological system embodies different forms of expression which do not always necessarily oppose the whole. It is in this context that the notion of fragmentation has been revised. Lately, the notion of fragmentation exposes its new positive and previous negative connotations:

\footnotetext{
The idea of fragmentation has often been invoked as a general description of life in the modern era, encompassing all aspects of experience from social traditions to religious and philosophical systems to aesthetic forms. The concept itself is opposed to that of totality- whether as a description of the self or subject, the system of values we inhabit, or the material experiences of every day life [...] For many, especially those invested in particular forms of essentialism, or belief in transcendent forms of aesthetics, morals, or political action, fragmentation is much lamented. For others, especially those who espouse notions of decentering or indeterminacy [...] fragmentation is not necessarily in and of itself a deleterious state of affairs and can even be celebrated (Childers 1995: 117).
}

In this definition, the traditional approach to fragmentation presents itself as the opposite of totality, and totality is regarded as a form of transcendental and essential truth, universally accepted, to the point of being formally acknowledged and transmitted by current cultural institutions such as the church, family, and formal school systems. This "truth" must function in equally effective ways for all human beings worldwide. The term fragmentation, then, acquires a negative perception in fixed, hegemonic systems of thought. On the contrary, post-modern and more recent approaches provide a new, deconstructed view of fragmentation which is not only positive, but also gives the term the qualifications of a necessary practice which accounts for the appreciation of difference within systems, promotes the idea of plurality and expands the types of relationships among all forces that compose a social system or group. 
These new approaches to fragmentation offer possibilities of synthesizing generalizations regarded as universal into more specific and particular ways of representation. Theorist Trinh T. Minh-Ha proposes fragmentation as a means of living with differences. Within the fragment, a subject is differentiated and keeps her/his distinctive features. Metaphorically, the fragment represents a differentiated individual who may acknowledge the existence of other fragments or individuals. The attempt to homogenize fragments encompasses the notion of wholeness. Trinh T. Minh-Ha restates the definition of the whole saying that it is not definitive, that it is composed of fragments, and that these fragments are not necessarily opposites among themselves:

\begin{abstract}
It's not a question of fragmentation versus synthesis but rather, of how one understands what happens within the notion of fragmentation. If one sees a fragment as being the opposite of a whole, then I have no affinities with the term, since it carries with it a compartmentalized worldview. But if a fragment stands on its own and cannot be recuperated by the notion of a totalizing whole, then fragmentation is a way of living with differences without turning them into opposites, nor trying to assimilate them out of insecurity. (157)
\end{abstract}

Difference becomes a key term within this view of fragmentation, for it is differentiation that determines and frames a fragment in the integration of any system. By incorporating the recognition of differences and also by opening possibilities for plurality, the abstract and general cedes space to the concrete and particular, where traditionally marginalized agents such as minority groups like homosexuals, lesbians and the elderly have been positioned. Now, they are given the chance to articulate their voice within a system. The universal breaks into the contingent and other shifting categories such as the local, and this rupture provides a chance for incorporating other views that may differ from some hegemonic truths. Cornell West confirms these assumptions:

\footnotetext{
Distinctive features of the new cultural politics of difference are to trash the monolithic and homogeneous in the name of diversity, multiplicity and heterogeneity; to reject the abstract, general and universal in light of the concrete, specific and particular; and to historicize, contextualize and pluralize by highlighting the contingent, provisional, variable, tentative, sighting and changing (Seidman 1995: 65).
}

The politics of difference are means of acknowledging difference in representations. These politics are re-structuring the ways of relating, behaving and conceiving the human experience. Fragments are basically constituted by difference and become necessary for the operation of systems. Thus, the ideas about fragmentation, difference, and the borders surrounding fragments analyze new perceptions about relationships in micro-systems, such as interpersonal relationships, and in a macro-systems such as social relationships that may possibly be found in narratives, providing a wide range of opportunities to interpret and theorize experience threatening conventions and paradigms.

The new approach to the notion of fragmentation precisely represents the changes and challenges in culture which shelter diverse ideological practices. However, without the application of the notions of borderlands, the clash of fragmented ways of being has often led to separation, an emotional or physical separation among members of families and culturallyrelated groups that may even end in forms of abuse and violence. To illustrate, the rates of dysfunctional families have increased worldwide lately: parents are divorced, the biological fathers distant from their children, and biological mothers prioritizing jobs, lovers, and other interests above their families. 


\section{Politics of Difference and Life in the Borders}

In his essay "The New Cultural Politics of Politics of Difference," at a macro-level, Cornell West states that the effects of differentiation have promoted a consciousness about other not acknowledged, disregarded parts or fragments, which are equally important within the composition of any type of social system. West affirms that:

\footnotetext{
what constitutes difference, the weight and gravity it is given in representation and the way in which highlighting issues like exterminism, empire, class, race, gender, sexual orientation, age nation, nature, and region at this historical moment, acknowledges some discontinuity and disruption from previous forms of cultural critique. To put it bluntly, the new cultural politics of difference consists of creative responses to the precise circumstances of our present moment-especially those of marginalized agents. (qtd in Seidman 1995: 65)
}

The assumptions of the New Cultural Politics of Difference refer to poststructuralist "studies of difference in race, gender, and sexual preference" (Childers 1995: 83) which promote the practices of difference and seek to "assert the privileges of multiplicity and diversity over homogeneity" (Childers 1995: 84). With these practices, they "aim not only to criticize representations that obscure difference, in the name of dominant cultural traditions but also to claim a space within the field of representation for previously excluded minorities" (Childers 1995: 84). West also proposes the constant search for an opening in hegemonic ways of thinking in order to establish differentiation. He affirms:

\footnotetext{
The new politics of difference are neither simply oppositional in contesting the mainstream for inclusive, nor transgressive in the avant- gardist sense of shocking conventional bourgeois audiences. Rather, they are distinct articulations of talented contributors to culture who desire to align themselves with demoralized, demobilized, depoliticized and disorganized people in order to empower and enable social action and to enlist collective insurgency for the expansion of freedom, democracy and individuality. (Seidman 1995: 66)
}

The attempts of the politics of difference to incorporate new previously marginalized agents into equally important positions of hegemonic thought in any social system constitute a basic aim. However, application of the theoretical proposals of the politics of difference may deviate from its primordial aims. The demoralized, demobilized, depolicitized and disorganized people alluded by West, as well as all other human beings, are given space to articulate any type of discourse which may incite only the fulfillment of egotistic interests and encourage destruction and violence. Discourses justified by difference may articulate destructive ways of thinking and relating. In this context, the enunciation of differences and their claim for recognition and acknowledgement become a double-edged sword. A clear illustration of this dichotomy is present in the discourse of hate explored by professors Janis Judson and Dona Bertazzoni in the book El derecho, los medios de comunicación y la cultura. They explore the ways of articulating a discourse originated from violence, revenge and hate and its destructive effects in society. Judson and Bertazzoni illustrate the discourse of hate citing the conformation of social groups such as the Kukus Klan and of individuals like Hitler and George Bush (2002: 2). With this danger in mind, the notion of fragmentation needs to be implemented with other practices that not only encourage differentiation, but at the same time, provide space for peaceful interaction among different ideologies. This is a space provided for the process of constructing identity, a place for transformation in which the self and the other negotiate their welfare in consensus. This place is the metaphorical space of borderlands. 
Trinh T. Min-Ha complements the notion of fragmentation with the notion of borders, or, as this notion has been called by other theorists, borderlands. Trinh goes beyond the practices of differentiation and acknowledgement and heads towards the borders of fragments, defining them as the space of relating and constructing identity. For this theorist, the process of construction of identity emerges from the practices of fragmentation and differentiation because of the interaction of multiple factors and traits within a hybrid context. The process is in constant movement and progression in the spheres of inquiry, change, and transformation, taking into account otherness as Trinh points out:

\footnotetext{
fragmentation is here a useful term because it always points to one's limits. Since the self, like the work you produce, is not so much a core as a process, where one finds oneself in the context of cultural hybridity, always pushing one's questioning of oneself to the limit of what one is and what one is not. (158)
}

In this process, the limits of fragments range from individual traits (what one is) to the reflection of the traits of the other (what one is not). The limits or borders are the space where the process of relating and constructing identity takes place.

\title{
3.1. The Border and Borderlands: Spaces of Tolerance
}

Traditionally, the notions of border and borderlands have been associated with national and international literatures that create literary productions within countries and their limits. However, the notion of borders has now expanded and includes many areas related to cultural practices. In the conference held in the University of Massachusetts at Amherst called "Borderlands: Remapping Zones of Cultural Practice and Representation" (2000), the notion of borderlands was redefined as follows:

\begin{abstract}
we take Borderlands to be those in-between places defined by the flow of people, labor, capital, information, and cultural products across borders, physical and otherwise, both within and between cultures [...] Because Borderlands are social scenes and places that people inhabit, they are also sites where ways of relating, feeling, and imagining are articulated into new constellations of social identities, practices and subjectivities (2000: 1).
\end{abstract}

Within this definition, it is important to note the existence of borders as a prior condition to the conception of borderlands. Trinh conceives of the border as the metaphorical line that stands between fragments. The fragment constitutes the frame of one's own personal limits and differences; its borders constitute the space of recognition of other fragments as well. Trinh defines this space as "a way of living at the borders, a way of living with differences [...] borders are diverse recognitions of the self through difference, and unfinished, contingent, arbitrary closures that make possible both politics and identity" (157).

Discussing the notion of borders, Emily Hicks, professor at the San Diego State University, reaffirms in her article "Border Writing and The Subject" that "the border crosser is both the self and the other. The border crosser subject emerges from double strings of signifiers of two sets of reference codes from both sides of the border" (DiBella 83). The border becomes the space of recognition in the first place, a space of differentiation, and finally, a space of transformation either by the practices of rejection or the practices of acceptance and learning. Trinh confirms that the experience in the border involves movement such as "stretching" in order to reach out beyond the limits: "work at the 
borderlines of several shifting categories stretch out to the limits of things, learning about [her] own limits and how to modify them" (137). According to her, this movement provokes change and transformation. Trinh also explains the particular individual experience that takes place in the borders:

\begin{abstract}
To move inside oneself, one has to be willing to go intermittently blind. To move toward other people, one has to accept to take the jump and move ahead blindly at certain moments of inquiry. If one is not even momentarily blind, if one remains as one is from the outside or from the inside, then it is unlikely that one would be able to break through that moment where suddenly everything stops; one's luggages are emptied out; and one fares in a state of non-knowingness where the destabilizing encounters with the "unfamiliar" or "unknown" are multiplied and experienced anew. (119)
\end{abstract}

In this process, a subject has to be willing to inquire about his/her own reality within her/his own fragmented space. The frame of the fragment comprises the subject's cultural and individual baggage, which in the end is what makes the subject different from others (as one is from the outside or from the inside). Its borders are the space where the subject makes a jump to otherness. Moreover, the unfamiliar and unknown become the borders and fragments of otherness. Blindness or a denial of the self's cultural baggage becomes necessary for recognizing others, trying to understand their differences and acknowledging them. The point where experience anew becomes the space in the borders where transformation and learning take place, a place where the subject is actively constructing her/his identity.

Trinh's theoretical proposal to explain the process of constructing identity differs from the prevailing notion of this identity process proposed by Jacques Lacan. Lacan bases his proposal of the process on the spatial identification of the self in a mirror, on the signifying system of language where a child identifies her/himself. This critic affirms that:

\footnotetext{
From the point of view of the mirror stage, the subject becomes established in the realm of the Symbolic, the realm of language and representation, and this relies on the recognition of the other in the mirror, that is both oneself and not-oneself, as a representative figure for the entry of the subject into the Symbolic. (Green-Lebihan 165)
}

This proposal necessarily involves visual recognition, for it is through the look or the gaze that the self becomes aware of its reflection in the mirror. In contrast, Trinh proposes the addition of blindness as a necessary step in recognition and transformation, for it is through it that the subject momentarily nullifies her/his own cultural luggage and, at the same time, tries to acknowledge the other's subjectivity. Trinh also metaphorically states that even if the mirror is blurred, the subject might still be there, suggesting that the visual connection of the self and its reflection might not be extremely necessary but complementary. It is important to notice that in Trinh's proposal for constructing identity, there has to be some sort of awareness or consciousness of the self and of the other to operate successfully in the border. With the acknowledgments of other fragments and borders, the politics of difference operates in constant negotiation between one subject and another in borderlands, thus making relationships dynamic. Hence, metaphorically, the border provides a space where each fragment acknowledges the existence of the other and establishes conditions for interrelation, communication and growing. Borderlands are places of interaction where all types of discourses are not only recognized and acknowledged but also revised, questioned and probably changed. They propitiate an implied understanding among fragments because, metaphorically speaking, fragments represent the agents, who 
must momentarily empty out their own cultural baggage in order to try to understand the space of the other. As a consequence, interpersonal and social relations become negotiable and constructive at the borders. In narratives, the representation of borders is mainly developed through characterization.

With the conceptualization of fragmentation out of the deconstruction and decentralization of the notions of essentialism, hegemony, and the center-totalitarian systems, the proposal of new forms of thematic development and style in literary discourses has proven to be assertive, especially if representation is complimented with the notion of borderlands. In contemporary literary works, such as those published by authors like Ann Beattie, Leonard Cohen, James Kelman, Jack Mathews, T. Coraghessan Boyle, and Gregory Burn, among others, fragmentation has served to portray that distancing from the conventional to support the new fresh modes of representation which provide spaces to present difference. Contemporary perspectives of realities must be plural, diverse, and multiple, as worldviews have acknowledge difference within cultural hybrids positively. Correspondingly, literary discourse either using style, characterization, or thematic development, or all, must embody difference. Subsequently, with the acknowledgement of difference, the construction of identity in the neutral spaces provided borderlands asserts a more tolerant and open disposition of connection among human beings-a current need in this convulsive, violent, discriminatory world.

\section{Bibliography}

Bertazoni, Dona. and Janis Judson. 2002. "El derecho, los medios de comunicación y la Cultura”. La Nación. August 30: Viva 10.

"Borderlands: Remapping Zones of Cultural Practice and Representation. Department of Communication.” University of Massachusetts 2000 <http:/www.umass.edu/grads/ program/index.shtml>.

Childers, Joseph and Gary Hentzi (eds.). 1995. The Columbia Dictionary of Modern Literary and Cultural Criticism. New York: Columbia UP.

Di-Bella, José Manuel, Sergio Gómez Montero and Harry Polkinhorn (eds.). 1987. Literatura de frontera. California: San Diego State University.

Green, Arthur. 1952. Sociology. An Analysis of Life in Modern Society. New York: McGrawHill Company Inc.

Hicks, Emily. 1987. "Border Writing and The Subject.” En: José Manuel Di- Bella, Sergio Gómez Montero and Harry Polkinhorn (eds.).

Makaryk, Irena R. 1994. Encyclopedia of Contemporary Literary Theory. Toronto: University of Toronto Press. 
Meyers, Kari and Gilda Pacheco. 2003. The Perceptive Process: An Introductory Guide to Literary Criticism. $1^{\text {st }}$ Ed. San José: Editorial de Universidad de Costa Rica.

Seidman Steve (ed.). 1995. The Postmodern Turn. New Perspectives on Social Theory. New York: Cambrige University Press.

Trinh T., Minh-Ha. 1992. Framer Framed. Great Britain: Routledge. 